\title{
The Sustainability Potential of the Humanitarian Professional Today
}

\author{
Fatimet Khuako \\ Federal state budgetary educational institution of higher \\ education \\ Maykop state technological university \\ Maykop, Russian Federation \\ Larisa Bzegezheva \\ Federal state budgetary educational institution of higher \\ education \\ Maikop state technological university \\ Maikop, Russian Federation \\ bzegezheva@yandex.ru
}

\author{
Svetlana Kirzhinova \\ Federal state budgetary educational institution of higher \\ education \\ Maikop state technological university \\ Maikop, Russian Federation \\ kirzhinova.svetlana@yandex.ru
}

\author{
Marietta Bolokova \\ Federal state budgetary educational institution of higher \\ education \\ Maikop state technological university \\ Maikop, Russian Federation \\ bolokova@rambler.ru
}

\begin{abstract}
The purpose of the work is to look, the comparison and the partly generalization of the conditions, which need for staying live of humanitarian professionalism in the modern world. To starting from the problem of humanitarian acknowledge' deficit, and also it's neglect on the science and social fields (for example, in the Russia), the article's authors, to remembering the research works on the theme, are turning to question. With the base on the thesis about the necessary change of the value's priority in the any continue social line, authors however are present the hypothesis: it is the possibility of save the most strong elements. And so version accompanies by the steadiness and the perspicacity of humanitarian acknowledge, which builds the whole range of the demands to the professional, what is analyzing in the article. The paper builds a possible modern model of humanitarianism in the labor market, able to provide a professional approach in various industries.
\end{abstract}

Keywords: the modern time, humanitarian science, professional demand, sustainability

\section{INTRODUCTION}

In the modern global science, talking about professional researcher $[1,2]$, is a real needing in the strong attention to indexes of science effective. For example, so reviewer of researchers, who interesting in this problem, doing in their work by G. Petrova and others: «Speaking about the Russian authors working in the field of university professional education, Prokhorov (2011), Shulman (2001), Kostyukevich (2001), Gudkhart (2006) and others should be mentioned». At the same time, it is necessary don't leave without attention the direct criteria, which include the material's finding, the writing of work, the present of ready work. Those plane-line is must to be takes, but not takes into account of the modern by Russia National system of qualifications. This official sciencemethodic complex is turn to systematization of needing knowledge, skill and ability. Moreover the classification here bases on the activity's list of competences, which have to use of the professional (in particular, the economic). So activitylist is includes: scientific-research, scientific-technical, innovation, scientific-enlighten, scientific-expert, pedagogical activity (classification E. Karavaeva, O. Vorobjeva, V. Tyshkevich) [4]. Even the interest of government programs in Russia is noticeable in this respect. As evidenced about that in the going year E. Volodarskaya, «In the frame of that hole system is doing the work, which forms the United branch qualification's limit on the field of researches, projects and education, including the preparation of science personnel». However is boring some of questions the professional face of workers, which doing the build of that system, because those information is fully invisible from public's eyes. At the same time with the whole tendentious of correcting the scientificresearch competition don't less interest has their humanitarian element. That is why it loosed today the needing respect in the technological and practical world. For example about that citied by G. Petrova and others: «All authors emphasize that nowadays the higher education experiences great transformations in its criterial bases, humanitarian criterion being one of them». Or about the same we're founding remark from J. Chan and others: «While many organizations lack specific protocols and policies, reports over the past 5-6 years have shed light on existing challenges despite the excitement surrounding humanitarian technologies, ways of 
working and future opportunities». A lot of experimental results and analytical generalizations on the humanitarian crisis today are also in the articles of other foreign and Russiaresearchers [7, 8, 9]. At the same time, economic issues that are at the intersection with the strengthening of the humanitarian sphere are also taken into account $[10,11,12]$. The conceptual apparatus is also analyzed and clarified with the proposals of a single holistic approach to new-sounding concepts (for example "new humanism" by L. Yampolskaya) [13]. Moreover, since traditionally and invariably the conditional result of progressive (including humanitarian) activities must be the identification and presentation of the national code of the constructive qualities of traditional culture, the actual lack of work in this direction determines the relevance of our subject.

\section{METHODS}

In that case we prefer traditional humanitarian and the most popular science methods: observation, comparison, analyze, with the possibility of accompanying comments, resume and total conclusion.

\section{RESULTS}

It is true: the mass mentality and it's accompanying components (including the humanitarian in the people moral) worried yet russian literature classic F. Dostoyevsky in his famous big novels (about hundred years before). It is we concern to the phenomenon of social conditioning of language. In one moment with the General planetary, everywhere using traits of mentality (which influence on the possible and potential understanding of reality (in particular, the economic)) may be the such lines of this tactic, which are causing by another reasons (more individualize, less linguistic). The language in the role of real activity component is clear defined on the meaning field as social life of this ethnic group in that time. Moreover, often precisely the producing public word language-model can to working with the out-mean, with the non-construction. Such, the having whole "non" texts and publications, often must to be strong only for social-politic life of person (mass, but not individual). On that field in the modern world we can to see the problem: the deviation from individual principle in the education (as school, as high). That certainly going to discrimination of humanitarian knowledge without of the student's intellect and professionalism (in particular, the economic). As talking about this question modern researchers G. Petrova and others, «There is also a question about humanitarization of university education as one of its primary criteria. Humanitarization, to be more exact, serious transformations of this university criterion are connected, first of all, with the mass nature of education, which became its characteristic feature in the $20^{\text {th }}$ century». In the analogical phrases are affecting the problems of double- professionalism: the naturalist and the humanist. That loyal, so long as «In classical epistemology, scientific cognition is determined primarily in the positivistic spirit as natural scientific». And we can agree with these mark of our Russian colleagues. Based on the past, planning for the perspective, we need to talk, that progressive leaps transform the cultural facets of civilization is not strictly positive, but not strictly negative. This happens as it is set by history. For example, in the law- structure of modern civilization was the turning-point, probably, the most appreciable for all past centuries. Thus, each coming time builds its own laws and canons, which may to control the personal and the mutual reality of peoples and society. But as thinks a modern researcher S. Belova, "“Alive", "lived", "life" - these wordsimages have become a meaningful basis for communication between teachers and students in the process of interpreting the work of literature". Such observation help for author, experimenting in Russia's schools, to come to the conclusion about the strongly of this moral- direction in the national mentality. The laws of reality in that time are demanding: the more talented individuals want to continue to feel the thirst for creativity. On the basis of the core criteria of national potential are saving over the years, but are building in new forms in the mobile social cases (in particular, the economic).

The official competences of the European Union existing today at the world level "are reflecting the codex of ideal worker, what worked out and confirmed by the unite of employers", and is the "dynamic combination of knowledge, understanding, skills and talent". In the case of turning strike to Russian Humanities we also have to remember so type of activity (unknown to other modern specialists) as: doing the standard document to a standard limit in accordance of standard directive. This activity type, which needs a very specific professional elements, goes often by forgetting the independence analyze of reality. The first step - the tractate and the explanation for own person, then - the reconstruction of own documents and programs for strong and often nonlogical laws of minimum standard. That scenario is usually today for RF- Humanities in the workplace (in particular, the economic). In this case, taking into account the Euro trends, but with a specific, Russian nuance, outlines the basis for the construction of a certain standard type of professional Humanities today.

\section{DISCUSSION}

Indeed, based on the already numerous experimental and socio-psychological studies, we can talk about the fact that the demand in the labor field will be a professional, not just versed in the details of their business, but also responsible, demanding of themselves and their colleagues, prepared as a Communicator and an initiative designer. However, all the requirements listed above in the paragraph are no less (if not more) relevant to techno-specialists, while the humanitarian specificity is still infringed in the clear definition of criteria. According to the modern philosopher A.V. Yurevich, "the "originality" of humanitarian knowledge, which traditionally consisted in the preference of life-meaning rather than practical problems, is partially atrophied". In addition, the identity of the Humanities highlighted above by A.V. Yurevich is noticeably doubled in the work we are interested in by the identity of the ethnos, already at the level of a specific national culture and economic. The aspect we have formulated here is probably somewhat exaggerated. However, if we take into account the mobility of chronological changes in society and allow a periodic departure from the praise of the former, any researcher of the Humanities must understand and 
be able to evaluate periodically emerging over time civilizational models and structures. For example, in the process of reading fiction identify fact present in the text image is performed by seeking personal associations, enabling them to grasp the essence and apply it already to my understanding of reality. And this perception scenario is typical for most other types of humanitarian activities. Moreover, mandatory human rights gain significance in the non-national legal field. In urban life, the so-called objects of humanitarian logistics, which are already applied in purely applied terms in extreme or potentially threatening situations, are used "for the distribution of these relief items in the aftermath of a disaster areas". At the same time, "emergency humanitarian logistics' facility location problem structures depend on the research goals". In addition, other modern works are also devoted to the issues of humanitarian logistics in the urban environment $[19,20,4,9]$. At the same time, laws are beginning to become somewhat more humane in the global humanitarian world controlled by human rights organizations. This suggests that legal law has been somewhat strengthened in relation to individual guarantees (in particular, the economic).

However, in our current work, we are more interested in the fundamental aspect of humanitarian knowledge than in the practical one, and therefore we will turn further to its expert capabilities, which are more in demand in the theoretical field. Expertise as a field of humanitarianism allows us to analyze the implementation of humanitarian laws in a particular area. The expert, as a professional, is figuratively called "flexible", that is, amenable to persuasion, but also able to convince himself, hearing the opponent, but also able to formulate himself. Such a requirement develops in the expert of the corresponding humanitarian thinking, which is very much in demand in his professional sphere (in particular, the economic). He, in fact, is a person who persistently "digs" in his problem, a master in his class, a virtuoso and deep analyst, a guide for others in the chosen field of activity. However, so safe, as shown by modern research, is the affiliation of a specialist to this path: for example, the detail analyze of the damage is in the article of I. Kunovskiy and another [21].

\section{CONCLUSiON}

The main task in the work of the University with this in mind is recognized as the formation of the graduate is not just a set of knowledge and skills, and attitudes to self-learning and self-organization (the continuous expansion and deepening of professional qualities). In such a series of particularly stands originality (including, and professional, and individuallypersonal). In this, as expected, should be interested in the future specialist himself, aimed at career growth. However, without experience of their own participation in it in search of new knowledge and learning techniques such a search, participation in scientific activities, such a task can not be solved. Nevertheless, as B. G. Yudin fears today, "at the same time, it remains unclear who and how will assess the presence and degree of expression in a particular individual of all these qualities". According to modern researchers, the most recognized personal characteristics of a humanist-professional are the following features that are included in three groups, such as: 1) at the level of perception: developing a single complex understanding of reality, cultural and moral approach to the situation; 2) in the internal-productive sphere: the need for recognition and understanding of what is happening; preference for cultural experience; development of their own position based on the existing personal value experience; 3 ) in the external communication environment: the desire for dialogue at any level; interest in resolving current situations. Here we can assume that a real expert-humanitarian, perhaps very wrong to expect the manifestation of the function of training professionals is assigned primarily to the University sphere, which is actively discussed in scientific and methodological works today [23]. Its implementation, of course, can not be determined by the professionalism of the teaching staff. Professional disciplines should be read by the relevant professionals belonging to the relevant departments. The criteria of the latter have always been considered to be the interconnectedness in the work of research and training components, the organization of work on the principle of science. However, at the same time, B. G. Yudin somewhat belittles the need for science in this case: "in many cases, it is for humanitarian expertise of paramount importance is the ability of the expert to adequately Express the interests, hopes and fears of the "ordinary man in the street"". Thoughtless and rigorous praise of humanitarian knowledge is unfruitful and sometimes even harmful. It creates both outright vulgar vulgarization and can become the basis of ideological and party perversions that are strictly incompatible with the scientific environment. Such excessive praise can be understood as a stupid extraneous template that should be ignored and never let go again. In ordinary classes of the humanitarian plan, S. Belova discovers a certain number of the most common problem components [14]. Among other questions of increased interest in "frozen" information on the subject, we will also add interest in sometimes implicit information concerning self-determination, being, sometimesand the meaning of life. However, for example, the third of them is very little different today, because this cognitive tendency disappears as it is defined in life. There is also a problem highlighted by $\mathrm{S}$. Belova that the individual pays little attention to intra-collective and interpersonal relations, which practically cancels Dialogic strategies and makes their bearer defenseless in the communication field. And therefore, as the individual develops, the ability to conduct logic of reasoning, not immediately answer questions, but rather correctly formulate them is very productive in further humanitarian practice. "Thanks to transition to the subjectoriented education, the senior becomes the subject of research activity while research activity acts as one of implementers of a further educational trajectory". Moreover, the disposition of humanitarians to expert activity may be motivated by the presence of the above-mentioned professional criteria. And it is the optimal presence of a professional portrait of an employee of this series that will create an integrated opinion about him: both as a conservative member of a labor corporate, and as a searching, aspiring creative researcher. Which is an adequate option in modern society (in particular, the economic). 
[13] L. Yampolskaya, "The Principle of Holistic Education and the Ideal of a Single Integrated Culture: Towards the Formation of an Approach", Procedia - Social and Behavioral Sciences, 2014, 166, pp. 488-496.

[1] M. Petrenko, "Tipological characteristics of the intercultural humanitarian educational technologies", Procedia - Social and Behavioral Sciences, 2017, vol. 237, pp. 520-526.

[2] N. Kachalov, A. Kornienko, R. Kvesko, Y. Nikitina, S. Kvesko, and Zh. Bukharina, "Integrated Nature of Professional Competence", Procedia - Social and Behavioral Sciences, 2015, vol. 206, pp. 459-463.

[3] G. Petrova, S. Gural, I. Brylina, A. Kornienko, A. Kornienko, U. Nikitina, and N. Kachalov, "Humanitarian Meaning of University Professional Education", Procedia - Social and Behavioral Sciences, 2015, vol. 206, pp. 455-458.

[4] E. Karavaeva, O. Vorobjeva, and V. Tyshkevich, "About the model of formation the research competence spheres, using by graduating students", Graduate education in the Russia, 2018, vol. 4, pp. 33-47.

[5] E. Volodarskaya, "Dynamics of the Criteria for Assessing the Research Performance", The sociology of science and of technologies, 2019, vol. 2 (10), pp. 120-128.

[6] J. Chan, L. Bateman, and G. Olafsson, "A people and purpose approach to humanitarian data information security and privacy", Procedia Engineering, 2016, vol. 159, pp. 3-5.

[7] J. Nilsson, M. Engstrom, J. Florin, A. Gardulf, and M. Carlsson, "A short version of the nurse professional competence scale for measuring nurses' self-reported competence", Nurse Education Today, 2018, vol. 71, pp. 233-239.

[8] H. Cranmer and M. Aschkenasay, "Building a professional global disaster response team at an academic health-care institution: the professionalisation of humanitarian health-care workers", Meeting Abstracts, published online May 10, 2014.

[9] S. Kesler, E. James, and M. Peck, "Humanitarian crisis simulation", Annals of Global Health, 2015, vol. 81 (1), 157 p.

[10] P. Verme and Ch. Gigliarano, "Optimal targeting under budget constraints in a humanitarian context", World Development, 2019, vol. 119, pp. 224-233.

[11] S. Oluwaseun Fadiya, S. Saydam, and V. Vany Zira, "Advancing big data for humanitarian needs", Procedia Engineering, 2014, vol. 78, pp. 88-95.

[12] J. Belliveau, "Humanitarian access and technology: opportunities and applications", Procedia Engineering, 2016, vol. 159, pp. 300-306.
[14] S. Belova, "The humanitarian expertise as a form of the pedagogue's professional reflexio", Bulletin of Kalmyk University, 2012, vol. 1 (13), pp. 34-41.

[15] S. Sharonova, "Competence approach and standards in education (comparative analysis of the EU and Russia)", Sociological Research, 2008, vol. 1, pp. 138-145.

[16] A. Yurevich, "The finest hour of humanitarians: social and humanitarian science in modern Russia", The questions of philosophy, 2003, vol. 12, pp. 113-125.

[17] H. Gosling and J. Geldermann, "A framework to compare OR models for humanitarian logistics", Procedia Engineering, 2014, vol. 78, pp. 2228.

[18] Ch. Boonmee, M. Arimura, and T. Asada, "Facility location optimization model for emergency humanitarians logistics", International Journal of Disaster Risk Reducation, 2017, vol. 24, pp. 485-498.

[19] J. Carlos Souza and D. Castro Brombilla, "Humanitarian logistics principles for emergence evacuation of places with many people", Procedia - Social and Behavioral Sciences, 2014, vol. 162, pp. 24-33.

[20] S. Tofighi, S. Torabi, and S. Mansouri, "Humanitarian logistics network under mixed uncertainty", European Journal of Operation Research, 2016, vol. 250, pp. 239-250.

[21] I. Kunovski, T. Donker, E. Driessen, P. Guijpers, G. Andersson, and M. Sijbrandij, "Internet-delivered cognitive behavioral therapy for posttraumatic stress disorder in international humanitarian aid workers: Study protocol", Internet interventions, 2017, vol. 10, pp. 23-28.

[22] B. Yudin, "From the ethical examination to examination of humanitarian", Knowledge. Understanding, Skill, 2005, vol. 2, pp. 126 135.

[23] L. Kazarina and I. Itsenko, "Teaching Model of Pupils' Research competencies condition assessment of pupils from humanitarianoriented classes of comprehensive school: Functional and Organizational Characteristics", Procedia - Social and Behavioral Sciences, 2015, 206. pp. 342-347.

[24] C. F. Agostinho, "Humanitarian logistics: how to help even more?", The International federation of Automatic Control, September 11-13, 2013. 